\title{
ESTIMATIVAS CONTÁBEIS E QUALIDADE DO LUCRO: ANÁLISE SETORIAL NO BRASIL ${ }^{1}$
}

\section{ACCOUNTING ESTIMATES AND EARNINGS QUALITY: SECTORAL ANALYSIS IN BRAZILI'}

\section{ESTIMATIVAS CONTABLES Y CALIDAD DEL LUCRO: ANÁLISIS SECTORIAL EN EL BRASIL ${ }^{1}$}

\author{
PAULO ROBERTO BARBOSA LUSTOSA \\ Professor Doutor em Contabilidade \\ Universidade de Brasília \\ prblustosa@gmail.com
}

\section{JOSÉ LÚCIO TOZETTI FERNANDES}

Mestrando em Ciências Contábeis - Programa Multiinstitucional e Inter-regional de Pós-Graduação em Ciências Contábeis (PMIRPGCC) - UnB / UFPB / UFRN

luciotozetti@yahoo.com.br

\section{DANIELLE MONTENEGRO SALAMONE NUNES}

Mestranda em Ciências Contábeis - Programa Multiinstitucional e

Inter-regional de Pós-Graduação em Ciências Contábeis

(PMIRPGCC) - UnB / UFPB / UFRN

danielle_nunes@hotmail.com

JOSÉ BONIFÁCIO DE ARAUJO JÚNIOR

Mestrando em Ciências Contábeis Programa Multiinstitucional e

Inter-regional de Pós-Graduação em Ciências

Contábeis (PMIRPGCC) - UnB / UFPB / UFRN

profjr2@gmail.com 


\section{repec}

Paulo Roberto Barbosa Lustosa, José Lúcio Tozetti Fernandes, Danielle Montenegro Salamone Nunes e José Bonifácio de Araujo Júnior

\section{RESUMO}

Diversos estudos vêm sendo realizados no exterior e mais recentemente, no Brasil, no sentido de se compreender melhor o comportamento e as relações existentes entre accruals, lucro líquido, fluxos de caixa e a qualidade dos lucros contábeis. Devido a sua utilidade para os mais diversos fins, o lucro e sua qualidade como parâmetro de mensuração de desempenho têm recebido cada vez mais atenção por parte dos usuários das informações contábeis. Assim, o presente estudo tem como finalidade analisar os accruals, como proxy para a qualidade do lucro, dos diversos setores da economia brasileira e verificar o impacto causado pelos accruals setoriais na percepção do mercado. Para tanto, foram formuladas e testadas, por meio de estudo empírico-análitico, duas hipóteses de pesquisas. A amostra foi constituída de séries históricas de variáveis contábeis e preços das ações, no período de 2003 a 2006, de 133 empresas listadas na Bovespa, de oito setores. Os resultados obtidos mostram que os níveis de accruals são diferentes para alguns setores da economia brasileira e que o mercado reage negativamente às variações nos níveis de accruals para a maior parte dos setores analisados. Contudo, não foi encontrada significância estatística nessa relação.

Palavras-chave: Earnings Quality. Accruals. Lucro Líquido. Fluxo de Caixa das Operações. Setores Econômicos.

\section{ABSTRACT}

Several studies have been performed abroad and more recently in Brazil in order to better understand the behavior and the relationship between accruals, net profit, cash flows and $f$ book earnings quality. Because of its usefulness for different purposes, profit and its quality as a parameter for measuring performance have received increasing attention from users of accounting information. Thus, this study aims to analyze accruals, as a proxy for the earnings quality, of the various sectors of the Brazilian economy and to check the impact caused by sector accruals in market perception. Therefore, two research hypothesis were formulated and tested through an empirical-analytic study. The sample was composed of time series of accounting variables and stock prices in the period 2003-2006, from 133 companies listed on Bovespa, the eight sectors. The results obtained show that levels of accruals are different for some sectors of the Brazilian economy and that the market reacts negatively to changes in the levels of accruals for most of the sectors analyzed. However, it was not found any statistical significance in this relationship.

Keywords: Earnings Quality. Accruals. Net Profit. Cash Flow from Operations. Economic Sectors. 


\section{RESUMEN}

Diversos estudios vienen siendo realizados en el extranjero y más recientemente, en Brasil, en el sentido de comprenderse mejor el comportamiento y las relaciones existentes entre accruals, lucro líquido, flujos de caja y la calidad de los lucros contables. Debido a su utilidad para los más diversos fines, el lucro y su calidad como parámetro de mensuración de desempeño ha recibido cada vez más atención por parte de los usuarios de las informaciones contables. Así, el presente estudio tiene como finalidad analizar los accruals, como proxy para la calidad del lucro, de los diversos sectores de la economía brasileña y verificar el impacto causado por los accruals sectoriales en la percepción del mercado. Para tanto, fueron formuladas y testadas, por medio de estudio empírico-analítico, dos hipótesis de investigaciones. La muestra fue constituida de series históricas de variables contables y precios de las acciones, en el período de 2003 a 2006, de 133 empresas listadas en la Bovespa, de ocho sectores. Los resultados obtenidos muestran que los niveles de accruals son diferentes para algunos sectores de la economía brasileña y que el mercado reacciona negativamente a las variaciones en los niveles de accruals para la mayor parte de los sectores analizados. No obstante, no fue encontrada significancia estadística en esa relación.

Palabras clave: Earnings Quality. Accruals. Lucro Líquido. Flujo de Caja de las Operaciones. Sectores Económicos.

\section{INTRODUÇÃO}

O debate sobre a qualidade do lucro contábil ocupa uma parcela importante das pesquisas acadêmicas. Sua abrangência inclui estudos nas áreas temáticas de gestão (contábil) dos resultados, nível de conservadorismo, previsão de resultados e importância relativa de medidas de desempenho da empresa (por exemplo, o lucro e o fluxo de caixa das operações). Há 10 anos, já era significativa a quantidade de estudos, normalmente empíricos, sobre gestão contábil de resultados, como pode ser visto no trabalho de Healy e Wahlen (1999), que revisa esse tipo de pesquisa.

É natural a ênfase de pesquisas que abordem, de maneira direta ou indireta, a qualidade do lucro contábil. Afinal essa parece ser a principal métrica gerada pelo sistema contábil, síntese das ações gerenciais e com reflexos importantes em vários tipos de contratos nos processos político e de mercado (WATTS; ZIMMERMAN, 1986).

A definição de qualidade do lucro contábil é, em si, um tema controverso. Muitas são as abordagens e interpretações. A avaliação qualitativa de algo pressupõe que se compare o objeto avaliado com referências previamente estabelecidas, de modo explícito ou implícito, na mente de quem avalia ou em um sistema informático. Nesse trabalho, será adotada a 
interpretação de qualidade do lucro de Pehman e Zhang (1998). Para esses autores, o lucro divulgado terá boa qualidade se "ele for um bom indicador de lucros futuros".

Essa referência traz implícita a noção de que o melhor lucro é aquele que representa ex ante as expectativas de fluxos de caixa futuros das decisões que os gestores tomam no presente. É um conceito de lucro econômico, obtido pela diferença entre dois estados de riqueza (valor da empresa) consecutivos, ambos mensurados pelo valor presente dos resultados econômicos futuros esperados (GUERREIRO, 1989). Por isso, o grau de conservadorismo contábil é em geral definido, como em Ohlson (1995), pela diferença entre o valor da empresa e o seu patrimônio líquido mensurado segundo as regras contábeis.

O critério que Pehman e Zhang (1998) adotaram para aferir a qualidade do lucro contábil remete à ideia de sustentabilidade do lucro. A qualidade do lucro contábil corrente seria proporcional à sua capacidade de se sustentar no futuro. Lucros correntes com alta (baixa) correlação com lucros futuros teriam alta (baixa) qualidade.

Essa interpretação fornece a base racional para a abordagem utilizada nesta pesquisa para aferir a qualidade do lucro. Sob o ponto de vista da realização em dinheiro, o lucro contábil periódico pode ser segregado em dois componentes: (i) o fluxo de caixa das operações (FCO); e (ii) as alocações feitas ao lucro que não se transformaram em dinheiro no período corrente. Em geral esse último componente é denominado de accruals, termo que também vem sendo utilizado com muita frequência no Brasil, nas pesquisas acadêmicas dessa área temática.

Li, Lev e Sougiannis (2005) constataram, por meio de testes exaustivos, que capturavam a significância estatística e os fundamentos econômicos das estimativas que geram as alocações ao lucro contábil, "que há bastante evidência de que os accruals e as estimativas que eles incorporam não melhoram a qualidade da informação contábil, no sentido de aumentarem a previsão do desempenho empresarial". Sendo assim, os accruals não melhoram a previsão de fluxos de caixa futuros para além do que já é previsto pelo próprio FCO.

Logo, é razoável a hipótese de que se o FCO, uma medida objetiva de fluxo de caixa passado desprovida de qualquer estimativa, tem correlação similar à dos accruals discricionários (depreciação, provisão para devedores duvidosos, provisão para garantias concedidas, ativo e passivo fiscal diferido, etc.) com os fluxos de caixa futuros, então não deve haver associação significativa entre os accruals de diferentes setores econômicos, e nem entre estes e o retorno das ações, posto que esta última medida é uma proxy dos fluxos de caixa futuros. Isso deve ser válido inclusive quando os accruals dos diferentes setores econômicos são segregados por tamanho.

Nesse sentido, o objetivo desta pesquisa é verificar, suportado nas conclusões do estudo de Li, Lev e Sougiannis (2005), as diferenças entre os accruals ${ }^{2}$ médios relativos, segregados por tamanho, de empresas listadas na Bovespa pertencentes a diferentes 
setores, e como estes accruals setoriais se relacionam com o retorno acionário do respectivo setor.

\section{TEORIA E HIPÓTESES}

Diversos estudos têm procurado demonstrar que o lucro contábil é um melhor indicador da performance das empresas e, portanto, seria um indicador mais relevante para o mercado que o fluxo de caixa das operações (SLOAN, 1996; DECHOW; KOTHARI; WATTS, 1998; BLACK, 1998; NASIR; ABDULLAH, 2004). De acordo com o SFAC n. ${ }^{0} 1$ (FASB, 1978, p.19), "[...] informações sobre o lucro da empresa e seus componentes mensurados pelos accruals contábeis geralmente fornecem um melhor indicador do desempenho da empresa do que as informações sobre entradas e saídas correntes de caixa." (tradução nossa).

Já para Lustosa e Santos (2006), o lucro contábil (LC) e o fluxo de caixa das operações (FCO) podem ser considerados variáveis de representação do desempenho da empresa em diferentes dimensões: o primeiro (LC), em uma dimensão econômica, tendo em vista a utilização do regime de competência; e o segundo (FCO), em uma dimensão financeira, pelo regime de caixa.

Nesse sentido, Chan et al. (2006) afirmam que os lucros e os fluxos de caixa podem divergir devido aos procedimentos contábeis relacionados com o momento e o montante das receitas e despesas (o reconhecimento das receitas e o princípio da confrontação), não sendo necessariamente baseadas nas entradas e saídas de caixa. Essa acepção é corroborada por Schroeder, Clark e Cathey (2005) ao afirmarem que os lucros contábeis são diretamente influenciados pelos métodos de reconhecimento de receitas e despesas, pelas necessidades de confrontá-las em um determinado período e pelas deliberações da administração e seus interesses. Assim, os accruals poderiam ser definidos como a diferença entre o lucro contábil de uma empresa e o fluxo de caixa de suas operações (SLOAN, 1996).

Para Chan et al. (2006), a mensuração dos accruals contábeis constitui um tema que tem recebido bastante atenção nos últimos anos haja vista a importância dessa medida como possível indicador da qualidade do lucro e da avaliação patrimonial de uma empresa.

Os níveis de accruals poderiam servir, também, como medida do gerenciamento dos lucros, entendido como o esforço empreendido pelos dirigentes de uma empresa no sentido de influenciar os lucros divulgados em curto prazo, utilizando-se de técnicas contábeis agressivas, geralmente motivados por pressões pelo alcance de metas de lucro, de forma a não desapontar as expectativas do mercado; e para aumentar a remuneração quando baseada em planos de bonificação (SCHROEDER; CLARK; CATHEY, 2005; WATTS; ZIMMERMAN, 1986; CHAN et al., 2006). 
A proxy feita de accruals com qualidade do lucro, centra-se no conceito de que o lucro quando visto em conjunto com os níveis de accruals fornecem uma melhor estimação de fluxos de caixa futuros do que as informações dos fluxos de caixa correntes (WATTS; ZIMMERMAN, 1986; DECHOW; KOTHARI; WATTS, 1998).

Por exemplo, altos accruals associados a altos lucros (reconhecido com lucros de baixa qualidade) podem ser decorrentes da antecipação de receitas e postergação de despesas, aumentando, consequentemente, as contas "recebíveis" e "contas a pagar", e reduzindo o fluxo de caixa corrente. Assim, a avaliação de fluxos de caixas futuros com base nos valores isolados de lucro e fluxo de caixa corrente resultaria em um prognóstico errado de seus valores.

Portanto, conforme se extrai do exemplo, Chan et al. (2006) afirmam que os accruals são direcionados pelas mudanças no capital circulante não monetário. Esses autores acrescentam, ainda, que a necessidade de capital de giro difere entre os diversos setores da economia, influenciando os níveis de accrual. Logo, o potencial de influência dos accruals no retorno das ações pode variar de setor para setor. Assim, seguindo essa linha, a primeira hipótese da pesquisa a ser testada tem o seguinte enunciado:

H1: Dado que os setores econômicos têm necessidades diferenciadas de capital de giro, os níveis de accruals também serão diferentes entre os setores.

Contudo, considerando que o lucro contábil seria um melhor indicador do desempenho da empresa - conforme comentado por Schroeder, Clark e Cathey (2005) e documentado por Watts e Zimmerman (1986) - pesquisas têm encontrado que, apesar de os lucros divulgados influenciarem os preços das ações, esta influência é pouco significativa. Assim, estudos como os de Sloan (1996), de Richardson et al. (2001), de Haw, Qi e Wu (2001) e de Chan et al. (2006) têm demonstrado que os retornos anormais das ações podem estar mais associados aos níveis de accruals do que aos valores de lucro. Esses estudos mostram que o mercado percebe altos valores de accruals associados a grandes lucros de forma negativa.

Chan et al. (2006) argumentam que, devido às variadas necessidades de capital de giro entre as linhas de negócio, a informação presente nos accruals sobre as expectativas de retornos futuros seria provável de alteração, quando analisados em conjunto com essas necessidades. Nesse mesmo sentido, Dechow, Kothari e Watts (1998) afirmam que os efeitos dos accruals nos lucros anuais e na predição de fluxos de caixas futuros são prováveis de serem maiores quando observados pelos accruals do capital de giro. Espera-se, então, que o mercado reaja de forma diferente à variação dos níveis de accruals (de um período para o outro) entre os setores, como será testado pela segunda hipótese de pesquisa:

H2: O mercado brasileiro responde de maneira diferente aos aumentos dos níveis de accruals apresentados pelos diversos setores da economia. 


\section{PESQUISAS ANTERIORES}

O estudo desenvolvido por Costa, Teixeira e Nossa (2002) sintetizou os resultados apresentados por diversos trabalhos que discutiram e analisaram questões vinculadas à relação entre a qualidade do lucro contábil e a variação no preço de ações, no que se refere ao conservadorismo e aos accruals. Esses autores concluíram que há evidência clara de que ainda existem questões em aberto no que se refere ao problema da relevância em contraponto à confiabilidade dos accruals e ao papel do conservadorismo, como elementos primordiais para sustentação da qualidade do lucro contábil.

Dentre os estudos que tratam dos lucros contábeis, fluxo de caixa e accruals como indicadores de desempenho das empresas, podem ser citados os de Sloan (1996), de Haw, Qi e Wu (2001), de Dechow, Kothari e Watts (1998), de Black (1998), de Bradshaw, Richardson e Sloan (1999), de Richardson et al. (2001), de Nasir e Abdullah (2004) e de Chan et al. (2006) para mercados externos e o de Sales et al. (2007) para o mercado brasileiro.

Sloan (1996) verificou se os preços das ações refletiam informações referentes aos lucros futuros contidas nos componentes de accrual e de fluxo de caixa dos lucros correntes. Esse autor encontrou que a persistência da performance dos lucros está ligada aos montantes relativos dos componentes de caixa e accruals do lucro corrente. Contudo, os preços das ações operam como se os investidores não conseguissem identificar corretamente as diferentes propriedades desses dois componentes.

Haw, Qi e Wu (2001) investigaram o conteúdo informacional relativo e incremental contido nos lucros, fluxo de caixa das operações e accruals no mercado de capitais chinês. Os resultados demonstraram que os lucros possuem maior conteúdo informacional que os fluxos de caixa. O estudo revelou, ainda, que os accruals discricionários fornecem informação adicional àquelas contidas nos accruals não discricionários. No entanto, não foram encontradas evidências fortes de que os valores associados aos accruals discricionários são menores do que os valores associados aos accruals não discricionários, conforme resultados obtidos em estudos realizados em mercados desenvolvidos.

Dechow, Kothari e Watts (1998) propuseram um modelo explicativo da relação entre lucros, fluxos de caixa e accruals. Esse modelo sugere que os fluxos de caixa futuros das operações são mais bem antecipados pelos lucros do que pelos fluxos de caixa correntes.

O estudo desenvolvido por Black (1998) procurou identificar qual informação teria maior relevância para o mercado, o lucro contábil ou os fluxos de caixa, levando-se em consideração o ciclo de vida da empresa. Os resultados indicaram que nas fases de início das atividades, crescimento e/ou incerteza, os fluxos de caixa tendem a ser mais relevantes do que os lucros, ao passo que, no estágio de maturidade do ciclo de vida, são os lucros que apresentam maior relevância para o mercado. 


\section{repec}

Paulo Roberto Barbosa Lustosa, José Lúcio Tozetti Fernandes, Danielle Montenegro Salamone Nunes e José Bonifácio de Araujo Júnior

Já Bradshaw, Richardson e Sloan (1999) examinaram os pontos de vista de dois tipos de analistas de mercado/investimento no intuito de verificar se eles identificam antecipadamente as consequências dos accruals elevados. Os resultados mostraram que as previsões de lucros efetuadas por estes analistas não contemplavam as futuras reversões nos lucros causadas por estes accruals. Além disso, ao examinar os pareceres dos auditores independentes, a pesquisa revelou também a inexistência de evidências de sinalização por parte destes a respeito de possíveis violações dos princípios contábeis geralmente aceitos.

O trabalho de Richardson et al. (2001) buscou aprofundar os estudos de Sloan (1996) no sentido de identificar as fontes de informações dos accruals com relação à qualidade do lucro. Os resultados apontaram que as informações contidas nos accruals com relação à qualidade do lucro não estão limitadas aos accruals correntes analisados por Sloan, mas se estendem aos accruals não correntes. Os resultados revelaram, ainda, que as informações contidas nos accruals, com relação à qualidade do lucro, decorrem do crescimento em escala das operações e da diminuição da eficiência no uso dos ativos.

Nasir e Abdullah (2004) realizaram estudo no qual foram examinadas as medidas de accrual e fluxo de caixa, de forma separada e em conjunto, entre as empresas da Malásia. O resultado mostrou que o uso de medidas com base em lucros ou fluxos de caixa não servem para avaliar o desempenho das empresas da Malásia indo de encontro aos resultados de pesquisas anteriores.

Chan et al. (2006) investigaram diversas hipóteses, como a manipulação de lucros, o viés exagerado com relação aos futuros crescimentos e a "underreaction" às mudanças nas condições do negócio, para explicar o poder preditivo dos accruals. Os autores efetuaram, ainda, testes de robustez utilizando comparações entre setores e dados da bolsa de valores do Reino Unido. Entre os resultados encontrados, o estudo sugere que apenas um pequeno número de itens dos accruals (incluindo alterações em estoques) ajuda a predizer os retornos futuros.

Lustosa e Santos (2006) realizaram estudo em que foram testadas e comparadas as reações do mercado ao fluxo de caixa das operações tradicional, previsto na norma americana FAS-95, e o fluxo de caixa ajustado pelas diferenças permanentes com o lucro contábil, no intuito de identificar se o alinhamento entre o fluxo de caixa das operações e o lucro contábil das empresas é relevante para o mercado brasileiro. Os resultados deste estudo revelaram que o mercado reage, de forma mais favorável, ao fluxo de caixa das operações ajustado que ao tradicional.

Sales et al. (2007) realizaram pesquisa com o intuito de identificar uma possível correlação entre os accruals e os fluxos de caixa das empresas brasileiras obtendo, como resultado, indícios de que altos lucros contábeis acompanhados de grandes accruals refletem piores níveis de qualidade do lucro. Além disso, o estudo mostrou que as empresas com 
níveis elevados de accruals apresentavam lucros elevados e, de forma inversa, menores fluxos de caixa.

\section{PROCEDIMENTOS DA PESQUISA}

\subsection{Amostra}

A amostra do estudo é composta de empresas brasileiras de capital aberto organizadas de acordo com a classificação setorial feita pela Bolsa de Valores de São Paulo (Bovespa). Foram selecionadas empresas que:

a. possuíssem todos os dados disponíveis, necessários para a pesquisa (explicitados adiante);

b. não pertencessem ao setor financeiro devido à especificidade das informações contábeis desse setor.

Todas as variáveis contábeis foram coletadas no banco de dados da Economática ${ }^{\circledR}$ entre o último trimestre de 2000 ao quarto trimestre de 2006 (dados trimestrais). Os dados contábeis do período inicial compreendido até o quarto trimestre de 2001 foram utilizados para estimar o Capital Circulante Líquido das Operações, necessário para o cálculo do FCO (como será demonstrado posteriormente). A série histórica dos preços das ações foi coletada do quarto trimestre de 2001 ao quarto trimestre de 2006 para o cálculo do retorno das ações. Portanto, o período analisado neste estudo é do primeiro trimestre de 2002 ao último trimestre de 2006.

Assim, as empresas que não dispunham de todos os dados disponíveis a partir do último trimestre de 2000 foram excluídas da amostra, de forma a viabilizar o cálculo do retorno da ação e das variações das variáveis contábeis (primeiro requisito). Desse modo, foi desconsiderado da análise o setor de Tecnologia da Informação, o qual continha apenas duas empresas na amostra final entre as oito empresas previstas para este setor. Assim, a amostra final do estudo compreendeu 133 empresas dispostas em oito setores (entre os dez previstos na classificação setorial da Bovespa), perfazendo 2.660 observações no período.

\subsection{Operacionalização das variáveis}

No estudo de Sloan (1996), o accrual é definido como a diferença entre o lucro líquido (LL) e o fluxo de caixa das operações (FCO). Nesse sentido, quanto maior o valor dos accruals, maior será a diferença entre o lucro e o fluxo de caixa:

$$
\text { Accruals }=\mathrm{LL}-\mathrm{FCO}
$$

Como no Brasil não era obrigatória a divulgação da Demonstração do Fluxo de Caixa (DFC) para a série histórica utilizada nesse estudo, foi estimado o FCO utilizando como 


\section{repec}

Paulo Roberto Barbosa Lustosa, José Lúcio Tozetti Fernandes, Danielle Montenegro Salamone Nunes e José Bonifácio de Araujo Júnior

base o modelo proposto por Lustosa e Santos (2006). A equação (2) mostra o modelo de FCO adotado nesse estudo, calculado indiretamente a partir do Capital Circulante Líquido Gerado pelas Operações (CCLop):

$$
\mathrm{FCO}_{\mathrm{i}^{\prime} \mathrm{t}}=\mathrm{CCLOpi}_{\mathrm{t}_{\mathrm{t}}}-\Delta_{\mathrm{i}^{\prime} \mathrm{t}}(\mathrm{AC}-\mathrm{DISP})+\Delta_{\mathrm{i}^{\prime} \mathrm{t}}(\mathrm{PC}-\mathrm{FINANcp}-\mathrm{DEBcp}-\mathrm{DIV})
$$

onde:

- $\quad \mathrm{FCO}_{\mathrm{i}^{\prime} \mathrm{t}}=$ fluxo de caixa das operações da empresa i no período $\mathrm{t}$;

- $\quad$ CCLop $_{\mathrm{i}^{\prime} \mathrm{t}}=$ capital circulante líquido das operações, disponível na Demonstração das Origens e Aplicações dos Recursos - DOAR - da empresa i no período t;

- $\quad \Delta_{\mathrm{i}^{\prime} \mathrm{t}}(\mathrm{AC}-\mathrm{DISP})=$ variação do ativo circulante menos as disponibilidades, da empresa i no período $t$;

- $\quad \Delta_{p t}(P C-$ FINANcp - DEBcp - DIV $)=$ variação do passivo circulante menos financiamentos e debêntures de curto prazo, e dividendos a pagar, da empresa i no período t.

Segundo Lustosa e Santos (2006, p.7), esse modelo para o cálculo do FCO “[...] é uma proxy bastante aproximada do seu verdadeiro valor [...]", já que alguns valores do Realizável e do Exigível de Longo Prazo não estão incluídos no modelo, mas poderiam afetar o fluxo de caixa das operações.

Diferentemente de outros estudos sobre earnings quality, os quais calculam os accruals a partir da expressão proposta por Sloan (1996) ${ }^{3}$ e a partir de então determinam o FCO pela diferença entre o lucro líquido e o accruals, nesse estudo optou-se por, primeiro, calcular o FCO conforme a equação (2), e depois determinar o accrual pela diferença com o lucro líquido. Este procedimento metodológico visa mostrar como o FCO pode ser determinado para as empresas brasileiras de maneira indireta. Contudo, como a equação 2 utiliza um dado da DOAR para estimar o FCO e esta demonstração é divulgada apenas anualmente, foi feita uma estimativa do CCLop para cada trimestre com base na proporção do capital de giro líquido trimestral sobre $o$ ativo total.

Para o exame da primeira hipótese de pesquisa, os valores dos accruals, dos FCOs e dos lucros líquidos foram comparados entre os setores como proporção em relação à média dos ativos totais, tendo em vista que a magnitude do porte das empresas, dentro de cada setor e entre os setores, influencia no tamanho das contas contábeis. Este procedimento foi realizado em consonância com outros estudos que trabalham com variáveis contábeis (e.g. SLOAN, 1996; LUSTOSA; SANTOS, 2006; CHAN et al., 2006; SALES et al., 2007).

Outra medida de accrual calculada foi a variação dos níveis de accruals das empresas de um ano para o outro, conforme mostra a equação (3):

$$
\Delta A c r_{i, t}=\frac{\left(A c r_{i, t}-A c r_{i, t-1}\right)}{A c r_{i, t-1}}
$$


onde:

- $\Delta \mathrm{Acr}_{\mathrm{i}{ }^{\prime} \mathrm{t}}=$ variação do accrual da empresa i no período $\mathrm{t}$;

- $\quad$ Acri,t = valor absoluto do accrual (não dividido pelo ativo total médio) da empresa i no período t; e

- $\quad \operatorname{Acr}_{\mathrm{i}, \mathrm{t}}-1$ = valor absoluto do accrual da empresa i no período anterior.

Do banco de dados da Economática ${ }^{\circledR}$ foi coletado o preço da ação (de fechamento) de maior volume de negociação de cada empresa pelo valor original e ajustado por dividendos e proventos. O retorno da ação no período $\left(R_{\mathrm{i}^{\prime} \mathrm{t}}\right)$ foi calculado sob capitalização contínua, pela diferença relativa entre os logaritmos naturais da cotação da ação da empresa i no período $\left(P_{i, t}\right)$ e a cotação no período anterior $\left(P_{i,{ }^{\prime}}-1\right)$, como mostra a expressão (4):

$$
R_{i, t}=\Delta\left(\frac{P_{i, t}}{P_{i, t-1}}\right)
$$

As variáveis "retorno da ação" e "variação dos níveis de accruals" foram organizadas nos setores econômicos que representavam cada empresa. Essas variáveis foram utilizadas para a verificação da segunda hipótese de pesquisa.

\subsection{Testes Estatísticos}

O conjunto de valores referentes ao FCO, ao accrual e ao lucro líquido (relativos ao ativo total médio) de cada empresa, em cada ano analisado, foi organizado de acordo com o setor de atuação da empresa. As observações de cada setor foram distribuídas em partes iguais em cinco portfólios em ordem crescente dos accruals (quintis), denotando que, no primeiro quintil (portfólio) de cada setor, estão as observações com os menores accruals e, no último quintil, as observações com os maiores.

A separação em quintis foi realizada para verificar a correlação entre o accrual médio de cada portfólio com os valores médios do FCO e do lucro líquido, tendo em vista a teoria de que quanto maior os accruals acompanhados de maiores lucros, menor o FCO e mais baixa é a qualidade do lucro. Assim, deve-se esperar uma correlação positiva entre accruals e lucros nos quintis e, negativa entre accruals e FCOs. Dessa forma, o portfólio demonstrado pelo primeiro quintil mostraria as observações das empresas que tiveram os lucros de melhor qualidade, enquanto que no último quintil, os de baixa qualidade.

Para verificar a primeira hipótese de pesquisa desse estudo, foram realizados testes de média com as observações do primeiro e do último quintil entre os setores, para verificar se os accruals desses quintis são diferentes estatisticamente e em qual sentido.

Segundo Watsham e Parramore (1997), o teste de média unicaudal é utilizado somente quando há um interesse em verificar se a média de uma população é superior ou inferior a 


\section{repec}

Paulo Roberto Barbosa Lustosa, José Lúcio Tozetti Fernandes, Danielle Montenegro Salamone Nunes e José Bonifácio de Araujo Júnior

um dado valor. $\mathrm{O}$ teste foi conduzido de forma a verificar a significância da estatística t (stat t) a um nível de $5 \%$ de significância $(\alpha=0,05)$. Assim, o valor da stat $t$ positiva e significativa mostra que a média dos accruals (relativos ao ativo total médio) de um setor é maior do que o outro setor comparado; caso a stat $t$ seja negativa, o contrário também é válido (hipótese alternativa). Contudo, se a estatística t não for significativa, infere-se que a média dos accruals do quintil de um setor não é maior do que a do outro setor (hipótese nula do teste).

Como forma de verificar a segunda hipótese de pesquisa do estudo, foram realizadas regressões lineares simples para cada setor com o intuito de examinar o comportamento do retorno da ação das empresas dos setores às variações nos níveis de accruals. Esperase que o sinal do coeficiente beta seja negativo para todas as regressões, denotando que o mercado reage negativamente a altos accruals, conforme sugerido pela teoria. Assim, o modelo quantitativo assumiria a seguinte função:

Rst $=\alpha+\beta_{1} \Delta$ Accruals $_{\text {st }}+\varepsilon$

sendo negativo o sinal esperado para $\beta_{1}\left(\beta_{1}<0\right)$.

onde:

- $\quad \mathrm{R}_{\mathrm{st}}=$ retorno das ações das empresas do setor $\mathrm{s}$ no período $\mathrm{t}$;

- $\Delta$ Accruals $_{\mathrm{st}}=$ variação dos níveis de accruals das empresas do setor $\mathrm{s}$ no período $\mathrm{t}$.

\section{RESULTADOS}

A Tabela 1 apresenta a média dos fluxos de caixa operacionais e dos lucros líquidos, ordenados com base nos accruals contábeis e segregados por quintil. O primeiro quintil de cada setor contempla as observações com menores accruals contábeis. Em contrapartida, o último quintil inclui as observações que possuíam os maiores accruals.

Observa-se que à medida que os accruals aumentam, ao longo dos quintis, os lucros líquidos também aumentam, enquanto os fluxos de caixa diminuem. Tem-se, então, que os menores accruals são acompanhados de menores lucros líquidos e maiores fluxos de caixa, sendo o oposto também verdadeiro. Assim, verifica-se que no primeiro portfólio estão as observações de cada setor que apresentaram os lucros de melhor qualidade (accruals e lucros mais baixos e FCO mais altos); enquanto que no último estão as observações com lucros de qualidade mais baixa.

Na Tabela 2, são apresentados os resultados dos testes de médias dos accruals entre as observações com os lucros de melhor qualidade (primeiro portfólio) de cada setor. Os resultados mostrados são referentes aos testes dos setores da primeira coluna da tabela (variável 1 do teste), com os setores da primeira linha (variável 2), nessa ordem. Os resulta- 
dos mostram que no portfólio que contempla os lucros de melhor qualidade não houve uma diferença estatisticamente significante entre os accruals de um setor em relação ao outro para 19 dos 28 testes de médias realizados.

Verificou-se que os testes de médias entre os setores de Bens Industriais e de Construção e Transporte (primeira coluna) em relação ao setor de Consumo Cíclico (primeira linha) refutaram a hipótese nula, ou seja, existem evidências de que os accruals médios do primeiro quintil são diferentes. Adicionalmente, os valores das estatísticas t (positivos) mostram que a média dos accruals desses dois setores são maiores do que a do setor de Consumo Cíclico, denotando que os setores de Bens Industriais e de Construção e Transporte apresentaram lucros de baixa qualidade quando comparados com o setor de Consumo Cíclico no primeiro portifólio.

\begin{tabular}{|c|c|c|c|c|c|}
\hline $\mathrm{FCO}$ & 0,08949 & 0,04056 & 0,01612 & $-0,00411$ & $-0,06785$ \\
\hline \multirow[t]{2}{*}{$\mathbf{L} \mathbf{L}$} & $-0,01167$ & 0,04542 & 0,03953 & 0,05818 & 0,08014 \\
\hline & \multicolumn{5}{|c|}{ B. Construção e Transporte } \\
\hline Accruals & $-0,10140$ & $-0,01327$ & 0,00492 & 0,02589 & 0,09517 \\
\hline FCO & 0,09109 & 0,00850 & 0,00021 & $-0,02024$ & $-0,07855$ \\
\hline \multirow[t]{2}{*}{$\mathbf{L} \mathbf{L}$} & $-0,00754$ & $-0,00035$ & 0,00490 & 0,00961 & 0,01325 \\
\hline & \multicolumn{5}{|c|}{ C. Consumo Cíclico } \\
\hline Accruals & $-0,19598$ & $-0,03440$ & $-0,00446$ & 0,01843 & 0,09986 \\
\hline FCO & 0,05420 & 0,01781 & 0,01146 & $-0,00641$ & $-0,06092$ \\
\hline \multirow[t]{2}{*}{$\mathbf{L} \mathbf{L}$} & $-0,29208$ & $-0,02162$ & 0,01141 & 0,01480 & $-0,09142$ \\
\hline & \multicolumn{5}{|c|}{ D. Consumo Não Cíclico } \\
\hline Accruals & $-0,39928$ & $-0,03673$ & $-0,00855$ & 0,01602 & 0,15475 \\
\hline FCO & 0,12195 & 0,04700 & $-0,01457$ & $-0,00128$ & $-0,14610$ \\
\hline \multirow[t]{2}{*}{$\mathbf{L} \mathbf{L}$} & $-0,54273$ & 0,02841 & $-0,10398$ & 0,01957 & $-0,12835$ \\
\hline & \multicolumn{5}{|c|}{ E. Materiais Básicos } \\
\hline Accruals & $-0,12274$ & $-0,01915$ & 0,00220 & 0,02881 & 0,12033 \\
\hline FCO & 0,09882 & 0,03816 & 0,02018 & 0,00988 & $-0,05372$ \\
\hline \multirow[t]{2}{*}{$\mathbf{L} \mathbf{L}$} & $-0,00777$ & 0,04978 & 0,05416 & 0,06618 & 0,11031 \\
\hline & \multicolumn{5}{|c|}{ F. Petróleo } \\
\hline Accruals & $-0,20400$ & $-0,02142$ & 0,01791 & 0,04733 & 0,20551 \\
\hline FCO & 0,14769 & 0,04601 & 0,01467 & 0,00055 & $-0,09710$ \\
\hline \multirow[t]{2}{*}{$\mathbf{L} \mathbf{L}$} & $-0,00953$ & 0,08355 & 0,09406 & 0,10400 & 0,10767 \\
\hline & \multicolumn{5}{|c|}{ G. Telecomunicações } \\
\hline Accruals & $-0,12891$ & $-0,03268$ & $-0,00578$ & 0,01672 & 0,08405 \\
\hline FCO & 0,11693 & 0,03270 & 0,01072 & $-0,00011$ & $-0,05963$ \\
\hline \multirow[t]{2}{*}{$\mathbf{L} \mathbf{L}$} & $-0,00145$ & 0,00751 & 0,01250 & 0,02284 & 0,04637 \\
\hline & \multicolumn{5}{|c|}{ H. Utilidade Pública } \\
\hline Accruals & $-0,28713$ & $-0,02591$ & $-0,00746$ & 0,00964 & 0,27324 \\
\hline FCO & 0,28284 & 0,03813 & 0,01924 & 0,00209 & $-0,25195$ \\
\hline LL & 0,01753 & 0,02353 & 0,02333 & 0,01937 & 0,03758 \\
\hline
\end{tabular}


Com relação aos setores de Bens Industriais, de Construção e Transporte e de Consumo Cíclico, na primeira coluna, e o setor de Consumo Não Cíclico, na primeira linha da Tabela 2, observa-se que os resultados dos testes de médias também rejeitam a hipótese nula e apresentaram estatística t positiva. Isso significa que a média dos accruals desses setores é maior (lucro de baixa qualidade) que a do setor de Consumo Não Cíclico (ou vice-versa).

Portanto, esses resultados permitem afirmar que o setor de Consumo Cíclico apresentou lucro de melhor qualidade no período analisado do que os setores de Bens Industriais e de Construção e Transporte; e que o setor Consumo Não Cíclico mostrou lucro de melhor qualidade em relação a esses três setores. Também verifica-se que os setores de Consumo Cíclico e de Consumo Não Cíclico (primeira coluna) mostraram lucro de melhor qualidade quando comparados com os setores de Materiais Básicos e de Telecomunicações (primeira linha). Isso ocorre, pois a estatística t do teste de média entre esses setores foi negativa, ou seja, a média dos accruals no portifólio das observações com os lucros de melhor qualidade foi menor para aqueles dois setores.

Tabela 2 - Teste de média dos Accruals do primeiro portfólio

\begin{tabular}{|c|c|c|c|c|c|c|c|}
\hline Setores & $\begin{array}{c}\text { Construção e } \\
\text { Transporte } \\
\end{array}$ & $\begin{array}{c}\text { Consumo } \\
\text { Cíclico } \\
\end{array}$ & $\begin{array}{c}\text { Consumo } \\
\text { Não Cíclico } \\
\end{array}$ & $\begin{array}{c}\text { Materiais } \\
\text { Básicos } \\
\end{array}$ & Petróleo & $\begin{array}{c}\text { Telecomu- } \\
\text { nicações }\end{array}$ & $\begin{array}{l}\text { Utilidade } \\
\text { Pública } \\
\end{array}$ \\
\hline $\begin{array}{l}\text { Bens } \\
\text { Industriais }\end{array}$ & $\begin{array}{c}\text { Não Rejeita } \\
(-0,4813)\end{array}$ & $\begin{array}{c}\text { Rejeita } \\
(3,4708)^{* * *}\end{array}$ & $\begin{array}{c}\text { Rejeita } \\
(3,1533)^{* * *}\end{array}$ & $\begin{array}{c}\text { Não Rejeita } \\
(0,6248)\end{array}$ & $\begin{array}{c}\text { Não Rejeita } \\
(1,0919)\end{array}$ & $\begin{array}{c}\text { Não Rejeita } \\
(0,9083)\end{array}$ & $\begin{array}{c}\text { Rejeita } \\
(1,3449)^{*}\end{array}$ \\
\hline $\begin{array}{l}\text { Construção e } \\
\text { Transporte }\end{array}$ & & $\begin{array}{c}\text { Rejeita } \\
(3,3625)^{* * *}\end{array}$ & $\begin{array}{c}\text { Rejeita } \\
(3,2205) * * *\end{array}$ & $\begin{array}{c}\text { Não Rejeita } \\
(0,9093)\end{array}$ & $\begin{array}{c}\text { Não Rejeita } \\
(1,1876)\end{array}$ & $\begin{array}{c}\text { Não Rejeita } \\
(1,1381)\end{array}$ & $\begin{array}{c}\text { Rejeita } \\
(1,4094)^{*}\end{array}$ \\
\hline $\begin{array}{l}\text { Consumo } \\
\text { Cíclico }\end{array}$ & & & $\begin{array}{c}\text { Rejeita } \\
(2,1710)^{* *}\end{array}$ & $\begin{array}{c}\text { Rejeita } \\
(-2,6477)^{* * *}\end{array}$ & $\begin{array}{c}\text { Não Rejeita } \\
(0,0916)\end{array}$ & $\begin{array}{c}\text { Rejeita } \\
(-2,3741)^{* * *}\end{array}$ & $\begin{array}{c}\text { Não Rejeita } \\
(0,6875)\end{array}$ \\
\hline $\begin{array}{l}\text { Consu mo Não } \\
\text { Cíclico }\end{array}$ & & & & $\begin{array}{c}\text { Rejeita } \\
(-2,9943)^{* * *}\end{array}$ & $\begin{array}{c}\text { Rejeita } \\
(-1,5715)^{*}\end{array}$ & $\begin{array}{c}\text { Rejeita } \\
(-2,9219)^{* * *}\end{array}$ & $\begin{array}{c}\text { Não Rejeita } \\
(-0,7045)\end{array}$ \\
\hline $\begin{array}{l}\text { Materiais } \\
\text { Básicos }\end{array}$ & & & & & $\begin{array}{c}\text { Não Rejeita } \\
(0,9422)\end{array}$ & $\begin{array}{c}\text { Não Rejeita } \\
(0,2609)\end{array}$ & $\begin{array}{c}\text { Não Rejeita } \\
(1,2484)\end{array}$ \\
\hline Petróleo & & & & & & $\begin{array}{c}\text { Não Rejeita } \\
(-0,8688)\end{array}$ & $\begin{array}{c}\text { Não Rejeita } \\
(0,5338)\end{array}$ \\
\hline $\begin{array}{l}\text { Telecomunica- } \\
\text { ções }\end{array}$ & & & & & & & $\begin{array}{c}\text { Não Rejeita } \\
(1,2005)\end{array}$ \\
\hline
\end{tabular}

A estatística t (stat $t$ ), que determina a significância estatística do teste de médias está entre parênteses, abaixo do resultado da hipótese estatística Hzero, de que as médias das amostras testadas não são maiores ou menores;

(*) significativo a $90 \%$ de nível de confiança;

(**) significativo a $95 \%$ de nível de confiança;

(***) significativo a $99 \%$ de nível de confiança.

Na Tabela 3, são apresentados os resultados dos testes de médias dos accruals entre as observações com os lucros de qualidade mais baixa (último portfólio) de cada setor, mantida a mesma ordem de apresentação dos resultados descrita na Tabela 2. Em linha com o observado na tabela anterior, os resultados da Tabela 3 mostram que no portfólio das 
observações de accruals maiores (baixa qualidade do lucro) não houve uma significância estatística da diferença entre os accruals de um setor em relação ao outro para a maioria dos testes de médias realizados (24 de um total de 28 testes).

Os resultados dos testes de médias entre o setor de Consumo Não Cíclico e os setores de Bens Industriais, de Construção e Transporte e de Telecomunicações rejeitaram a hipótese nula, ou seja, os valores das estatísticas $t$, com significância a um nível de confiança de 95\%, mostram que o Consumo Não Cíclico apresenta média de accruals maior que os outros três setores analisados. Isso denota que, entre as observações de baixa qualidade do lucro, o setor de Consumo Não Cíclico teria accruals maiores e, portanto, um lucro de pior qualidade com relação aos setores de Bens Industriais, de Construção e Transporte e de Telecomunicações.

$\mathrm{Na}$ Tabela 4, são apresentados os resultados obtidos a partir das regressões entre os retornos das ações e as variações nos accruals contábeis das empresas dos setores analisados. Os betas encontrados apresentaram sinal negativo para seis dos oito setores analisados, confirmando uma relação inversa entre as variações nos accruals e os retornos acionários, conforme sugerido pela teoria.

Ressalta-se, entretanto, que os coeficientes encontrados não apresentam significância estatística para a situação em análise. Dessa forma, verifica-se que não existe relacionamento significativo entre as variações dos accruals contábeis e os retornos das ações, sugerindo que o mercado brasileiro, para os setores analisados, não reage a tais informações. Esses resultados corroboram com os estudos de Sales et al. (2007) para o mercado brasileiro e de Nasir e Abdullah (2004) para as empresas listadas na Bolsa da Malásia, mas diferente de outras pesquisas anteriores citadas nesse estudo.

Tabela 3 - Teste de média dos Accruals do último (quinto) portfólio

\begin{tabular}{|c|c|c|c|c|c|c|c|}
\hline Setores & $\begin{array}{c}\text { Construção e } \\
\text { Transporte }\end{array}$ & $\begin{array}{c}\text { Consumo } \\
\text { Cíclico }\end{array}$ & $\begin{array}{c}\text { Consumo } \\
\text { Não Cíclico }\end{array}$ & $\begin{array}{c}\text { Materiais } \\
\text { Básicos }\end{array}$ & Petróleo & $\begin{array}{c}\text { Telecomu- } \\
\text { nicações }\end{array}$ & $\begin{array}{c}\text { Utilidade } \\
\text { Pública }\end{array}$ \\
\hline Bens Industriais & $\begin{array}{c}\text { Rejeita } \\
(1,3331)^{*}\end{array}$ & $\begin{array}{c}\text { Não Rejeita } \\
(1,0102) \\
\end{array}$ & $\begin{array}{c}\text { Rejeita } \\
(-1,3135)^{*}\end{array}$ & $\begin{array}{c}\text { Não Rejeita } \\
(-0,2554) \\
\end{array}$ & $\begin{array}{c}\text { Rejeita } \\
(-1,3167)^{*}\end{array}$ & $\begin{array}{c}\text { Rejeita } \\
(1,5580)^{*}\end{array}$ & $\begin{array}{c}\text { Não Rejeita } \\
(-1,0393)\end{array}$ \\
\hline $\begin{array}{l}\text { Construção e } \\
\text { Transporte }\end{array}$ & & $\begin{array}{c}\text { Não Rejeita } \\
(-0,2447)\end{array}$ & $\begin{array}{c}\text { Rejeita } \\
(-1,8863)^{* *}\end{array}$ & $\begin{array}{c}\text { Não Rejeita } \\
(-1,2074)\end{array}$ & $\begin{array}{c}\text { Rejeita } \\
(-1,5991)^{*}\end{array}$ & $\begin{array}{c}\text { Não Rejeita } \\
(0,4821)\end{array}$ & $\begin{array}{c}\text { Não Rejeita } \\
(-1,1724)\end{array}$ \\
\hline Consumo Cíclico & & & $\begin{array}{c}\text { Rejeita } \\
(-1,7298)^{* *}\end{array}$ & $\begin{array}{c}\text { Não Rejeita } \\
(-0,9720) \\
\end{array}$ & $\begin{array}{c}\text { Rejeita } \\
(-1,5297)^{*}\end{array}$ & $\begin{array}{c}\text { Não Rejeita } \\
(0,6790)\end{array}$ & $\begin{array}{c}\text { Não Rejeita } \\
(-1,1413)\end{array}$ \\
\hline $\begin{array}{l}\text { Consumo Não } \\
\text { Cíclico }\end{array}$ & & & & $\begin{array}{c}\text { Não Rejeita } \\
(1,0498) \\
\end{array}$ & $\begin{array}{c}\text { Não Rejeita } \\
(-0,6907)\end{array}$ & $\begin{array}{c}\text { Rejeita } \\
(2,0640)^{* *}\end{array}$ & $\begin{array}{c}\text { Não Rejeita } \\
(-0,7695)\end{array}$ \\
\hline $\begin{array}{l}\text { Materiais } \\
\text { Básicos }\end{array}$ & & & & & $\begin{array}{c}\text { Não Rejeita } \\
(-1,2246)\end{array}$ & $\begin{array}{c}\text { Rejeita } \\
(1,4690)^{*}\end{array}$ & $\begin{array}{c}\text { Não Rejeita } \\
(-1,0051)\end{array}$ \\
\hline Petróleo & & & & & & $\begin{array}{c}\text { Rejeita } \\
(1,7287)^{*}\end{array}$ & $\begin{array}{c}\text { Não Rejeita } \\
(-0,4086)\end{array}$ \\
\hline $\begin{array}{l}\text { Telecomunica- } \\
\text { ções }\end{array}$ & & & & & & & $\begin{array}{c}\text { Não Rejeita } \\
(-1,2409)\end{array}$ \\
\hline
\end{tabular}

A stat $t$ está embaixo do resultado da hipótese estatística Hzero;

(*) significativo a $90 \%$ de nível de confiança;

(**) significativo a $95 \%$ de nível de confiança;

(***) significativo a $99 \%$ de nível de confiança. 
Vale destacar que a hipótese de mercado eficiente (HME) pressupõe que o mercado antecipa as informações contábeis, assim, nesse sentido, o mercado reagiria às informações divulgadas em relação aos accruals apenas se houvesse alguma surpresa em relação aos valores esperados. Os resultados obtidos podem ser, então, um indicativo de eficiência do mercado brasileiro, sendo necessários novos estudos para se verificar esse fato.

Tabela 4 - Resultados das regressões por setor

\begin{tabular}{|c|c|c|c|}
\hline Setor & á & $\hat{\mathbf{a}}$ & $R^{2}$ ajustado \\
\hline Bens Industriais & $\begin{array}{c}0,074457 \\
(5,764277)\end{array}$ & $\begin{array}{c}0,000239 \\
(0,266662)\end{array}$ & $-0,002920$ \\
\hline Construção e Transporte & $\begin{array}{c}0,071821 \\
(2,706466)\end{array}$ & $\begin{array}{c}-0,001281 \\
(-0,631130)\end{array}$ & $-0,003798$ \\
\hline Consumo Cíclico & $\begin{array}{c}0,065461 \\
(3,760500)\end{array}$ & $\begin{array}{c}-0,000023 \\
(-0,070843)\end{array}$ & $-0,002944$ \\
\hline Consu mo Não Cíclico & $\begin{array}{c}0,062689 \\
(3,650177)\end{array}$ & $\begin{array}{c}-0,000007 \\
(-0,040290)\end{array}$ & $-0,004580$ \\
\hline Materiais Básicos & $\begin{array}{c}0,098205 \\
(9,772689) \\
\end{array}$ & $\begin{array}{c}-0,000179 \\
(-0,630395) \\
\end{array}$ & $-0,000944$ \\
\hline Petróleo & $\begin{array}{c}0,077709 \\
(3,039615)\end{array}$ & $\begin{array}{c}-0,000263 \\
(-0,165889)\end{array}$ & $-0,012463$ \\
\hline Telecomunicações & $\begin{array}{c}0,015417 \\
(1,085051)\end{array}$ & $\begin{array}{c}0,000328 \\
(0,194145)\end{array}$ & $-0,004043$ \\
\hline Bens Industriais & $\begin{array}{c}0,067120 \\
(6,145659)\end{array}$ & $\begin{array}{c}-0,000221 \\
(-1,531686)\end{array}$ & 0,002802 \\
\hline
\end{tabular}

O modelo de regressão é representado pela expressão: $\mathrm{R}_{\mathrm{st}}=\mathrm{a}+\hat{a}_{l}$ ? Accruals $_{\mathrm{st}}+\varepsilon$;

As estatísticas $\mathrm{t}$, que determinam a significância estatística dos parâmetros da

regressão (á e $\hat{a}$ ), estão entre parênteses, embaixo de cada parâmetro.

Outro fator que pode explicar os resultados obtidos é o fato de a divulgação das informações contábeis ser ex post, ou seja, ocorrer após a negociação dos títulos. Dessa forma, seria necessário analisar a reação do mercado as variações dos níveis de accruals contábeis quando da divulgação das demonstrações para confirmar, ou não, a existência de relação entre as variáveis analisadas.

\section{CONSIDERAÇÕES FINAIS}

Esse trabalho se propôs a analisar a qualidade do lucro dos diversos setores econômicos, utilizando os accruals contábeis como proxy para o earnings quality, e verificar o impacto dos níveis de accruals apresentados pelas empresas dos diversos setores da economia na percepção do mercado brasileiro.

Os resultados apresentados confirmaram a primeira hipótese da pesquisa: "os níveis de accruals variam entre os setores da economia". Foi encontrado que, no grupo das observações com melhor qualidade do lucro (primeiro quintil), as observações dos setores de Consumo Não Cíclico e Consumo Cíclico apresentaram o menor nível de accruals, logo o lucro de melhor qualidade quando comparados com 5 e 4, respectivamente, dos 7 setores 
outros analisados. Já no portfólio composto pelas observações com lucros de qualidade mais baixa (último quintil), apenas o setor de Consumo Não Cíclico apresentou nível de accruals superior em relação a 3 dos outros 7 setores.

Para responder à segunda hipótese da pesquisa - "o mercado brasileiro responde de maneira diferente aos aumentos dos níveis de accruals apresentados pelos diversos setores da economia" -, foram realizadas regressões lineares entre as variações dos accruals e os retornos apresentados pelas empresas dos setores analisados. Os resultados obtidos não apresentaram significância estatística. Entretanto, o sinal apresentado por 6 dos 8 betas calculados foi negativo, indicando alinhamento com a teoria de que o mercado reage negativamente às variações dos accruals.

Ressalta-se que a utilização do modelo proposto por Lustosa e Santos (2006), para estimar o FCO, pode ser vista como uma limitação do estudo. Contudo, tendo em vista a não obrigatoriedade de divulgação da Demonstração do Fluxo de Caixa (DFC) para o período analisado, o referido modelo foi utilizado como proxy para a informação.

Por fim, percebe-se que existe uma lacuna na literatura brasileira sobre o assunto, sendo necessários outros estudos. Sugerem-se, pois, pesquisas para avaliar os accruals contábeis dos setores com relação aos componentes discricionários e não discricionários, bem como a utilização de dados trimestrais ou, ainda, semestrais. No mesmo sentido, poder-se-ia proceder à verificação do comportamento do mercado com relação às observações do primeiro e do último portfólio quando da divulgação das demonstrações contábeis (janela de eventos).

\section{REFERÊNCIAS}

BLACK, Erwin L. Which is more value relevant: earnings or cash flows? A life cycle examination. Working Paper. Arkansas: University of Arkansas, may/1998. Disponível em: <http://papers.ssrn. com/sol3/Delivery.cfm/98081804.pdf?abstractid=118089\&mirid=1> Acesso em: 15/jan/2009.

BRADSHAW, Mark T.; RICHARDSON, Scott A; SLOAN, Richard G. Earnings quality and financial reporting credibility: An empirical investigation. Social Science Research Network, Jul/1999. Disponível em: <http://papers.ssrn.com/sol3/papers.cfm?abstract_ id=170558. $>$. Acesso em: 15/jan/2009.

CHAN, Konan; CHAN, Louis K. C.; JEGADEESH, Narasimhan; LAKONISHOK, Josef. Earnings quality and stock returns. Journal of business, vol. 79, n 31, 2006. 
COSTA, Alessandra Cristina de Oliveira; TEIXEIRA, Aridelmo José Campanharo; NOSSA, Valcemiro. Conservadorismo, accruals e qualidade dos lucros contábeis. In: ENCONTRO NACIONAL DA ASSOCIAÇÃO NACIONAL DE PÓS-GRADUAÇÃO E PESQUISA EM ADMINISTRAÇÃO, XXVI, 2002, Salvador. Anais eletrônicos... Rio de Janeiro: ANPAD, 2002. Disponível em: <http://www.anpad.org.br/enanpad/2002/dwn/enanpad2002-ccg-1468.pdf>. Acesso em: 15/jan/2009.

DECHOW, Patricia M.; KOTHARI; S. P.; WATTS, Ross L. The relation between earnings and cash flows. Journal of Accounting and Economics, n 25, p. 133-16, 1998.

FINANCIALACCOUNTING STANDARDS BOARD (FASB). Statement of financial accounting concepts $n^{\circ} 1$ : Objectives of financial reporting by business enterprises. Connecticut: FASB, 1978. Disponível em: <http://www.fasb.org/st/\#cons>. Acesso em: 10/jan/2009.

GUERREIRO, Reinaldo. Modelo Conceitual de Sistema de Informação de Gestão Econômica: Uma Contribuição à Teoria da Comunicação da Contabilidade. 1989. Tese (Doutorado em Contabilidade). Faculdade de Economia, Administração e Contabilidade, USP, São Paulo, 1989.

HAW, In-Um; QI, Daqing; WU, Woody. The nature of information in accruals and cash flows in an emerging capital market: The case of China. The International Journal of Accounting, v 36, n 4, p. 391-406, 2001.

HEALY, P. M.; WAHLEN, J. M. A review of the earnings management literature and its implications for standard setting. Accounting Horizons, v. 13, n. 4, p. 365-383, dec/1999.

LUSTOSA, Paulo Roberto Barbosa; SANTOS, Ariovaldo dos. Importância relativa do ajuste no fluxo de caixa das Operações para o mercado de capitais brasileiro. In: CONGRESSO USP DE CONTROLADORIA E CONTABILIDADE, 6, 2006, São Paulo. Anais eletrônicos... São Paulo: FEA/USP, 2006. Disponível em: <http://www.congressoeac.locaweb.com.br/ artigos62006/400.pdf >. Acesso em: 10/jan/2009.

NASIR, Norita Mohd; ABDULLAH, Shamsul Nahar. Information provided by accrual and cash flow measures in determining firm's performance: Malaysian evidence. American Journal of Applied Sciences, vol 1, n 2, p. 64-70, 2004.

OHLSON, James A. Earnings, Book Value and Dividends in Security Valuation. Contemporary Accounting Research, v 11, n 2, p. 661-687, spring/1995. 
PENMAN, S. H.; ZHANG, Xiao-Jun. Accounting Conservatism, The Quality of Earnings, and Stock Returns. Social Science Research Network, dec/1999. Disponível em: <http:// papers.ssrn.com/sol3/delivery.cfm/991216301.pdf?abstractid=201048 >. Acesso em: 30/ jan/2009.

RICHARDSON, Scott A; SLOAN, Richard G.; SOLIMAN, Mark T.; TUMA, Irem. Information in accruals about the quality of earnings. Michigan: University of Michigan Business School, Set/2001. Disponível em: <http://home.business.utah.edu/actmp/wconf02/papers/ sloan.pdf>. Acesso em: 10/jan/2009.

SALES, Isabel Cristina. Henriques et al. Earnings quality: Análise empírica dos accruals contábeis no mercado de capitais brasileiro. In: ENCONTRO NACIONAL DAASSOCIAÇÃO NACIONAL DE PÓS-GRADUAÇÃO E PESQUISA EM ADMINISTRAÇÃO, XXXI, 2007, Rio de Janeiro. Anais eletrônicos... Rio de Janeiro: ANPAD, 2007. Disponível em: < http:// www.anpad.org.br/login.php?cod_edicao_subsecao=280\&cod_evento_edicao=33\&cod_ edicao_trabalho=7430>. Acesso em: 10/jan/2009.

SCHROEDER, Richard G.; CLARK, Myrtle W.; CATHEY, Jack M.. Financial accounting theory and analysis: Text readings and cases. 8th Ed. New Jersey: Wiley, 2005.

SLOAN, Richard G. Do stock prices fully reflect information in accruals and cash flows about future earnings? The Accounting Review, vol 71, n 3, p. 289-315, jul/1996.

WATSHAM, Terry J.; PARRAMORE, Keith. Quantitative Methods for Finance. London: Thomson Learning, 1997.

WATTS; Ross L.; ZIMMERMAN, Jerold L.. Positive accounting theory. New Jersey: Prentice-Hall, 1986.

\footnotetext{
${ }^{1}$ Trabalho apresentado e publicado nos anais do International Accounting Congress IAAER - ANPCONT $\left(3^{\circ}\right)$.

${ }^{2}$ Nesta pesquisa não se considerou a distinção entre os accruals discricionários e não discricionários com o intuito de manter-se base de comparação com o estudo de Chan et al (2006), os quais também analisaram a qualidade do lucro por setor para o mercado do Reino Unido.

${ }^{3}$ Expressão proposta por Sloan (1996) para cálculo do accrual:

Accrual $=\triangle \mathrm{AC}-\triangle \mathrm{PC}-\mathrm{DEP}$

$=(\Delta \mathrm{CR}+\Delta \mathrm{EST}+\triangle \mathrm{OAC})-(\Delta \mathrm{CP}+\Delta \mathrm{OPC})-\mathrm{DEP}$, onde
}

$\triangle \mathrm{AC}$ é a variação do ativo circulante não monetário; $\triangle \mathrm{PC}$ é a variação do passivo circulante excluído de financiamentos de curto prazo e imposto a pagar; DEP é a depreciação do período; $\triangle \mathrm{CR}$ é a variação de constas a receber; $\triangle \mathrm{EST}$ é a variação de estoques; $\triangle \mathrm{OAC}$ é a variação de outros ativos circulantes; $\triangle \mathrm{CP}$ é a variação de contas a pagar; $\triangle \mathrm{OPC}$ é a variação de outros passivos circulantes. 